\title{
An Abecedarian Approach with Aboriginal Families and Their Young Children in Australia: Playgroup Participation and Developmental Outcomes
}

\author{
Jane Page ${ }^{1} \cdot$ Megan L. Cock $^{1} \cdot$ Lisa Murray $^{1} \cdot$ Tricia Eadie $^{1} \cdot$ Frank Niklas $^{1,3}$. \\ Janet Scull ${ }^{2}$. Joseph Sparling ${ }^{1,4,5}$
}

Published online: 1 August 2019

(c) The Author(s) 2019

\begin{abstract}
New approaches to support the early learning for young Indigenous children are important to government policies across Australia. This study explores whether the Abecedarian Approach Australia ( $3 a$ ) intervention, with strong cultural adaptations, can boost young Aboriginal children's early language and learning skills, prior to preschool. Participants in this study were Aboriginal children attending playgroups, Families as First Teachers, in school settings in two remote communities in the Northern Territory. Implementation data on two components (Conversational Reading and LearningGames) of the Abecedarian Approach Australia (3a) intervention are reported, and the level of exposure the children had to the programme during the study period is analysed. Child outcomes were assessed on the Brigance Early Childhood Screen II for 149 children aged from 24 to 56 months. Children's language and early learning were associated with intervention dosage. Higher exposure to Conversational Reading and LearningGames predicted stronger language and overall development for young children. This study demonstrates that this intervention can be delivered effectively in playgroups in remote settings and is a meaningful and robust strategy to support early childhood learning, with potential to improve educational outcomes for young Aboriginal children in remote communities.
\end{abstract}

Jane Page

j.page@unimelb.edu.au

1 Melbourne Graduate School of Education, University of Melbourne, 100 Leicester Street, Parkville, VIC 3010, Australia

2 Faculty of Education, Monash University, 19 Ancora Imparo Way, Clayton, VIC 3800, Australia

3 Ludwig-Maximilians-University of Munich, Geschwister-Scholl-Platz 1, 80539 Munich, Germany

4 Frank Porter Graham Child Development Institute, University of North Carolina at Chapel Hill, Chapel Hill, NC 27599, USA

5 Abecedarian Education Foundation, 2505 Bartlett Circle, Hillsborough, NC 27278, USA 
Keywords Abecedarian - Early childhood education · Language outcomes ·

Cognitive academic outcomes $\cdot$ Indigenous population $\cdot$ Australia

\section{Résumé}

De nouvelles approches pour soutenir l'apprentissage en bas âge chez les jeunes enfants indigènes sont importantes pour les politiques gouvernementales à travers l'Australie. Cette étude examine si l'intervention Abecedarian Approach Australia $(3 a)$, avec de fortes adaptations culturelles, peut stimuler le langage et les aptitudes cognitives de jeunes enfants aborigènes, avant le préscolaire. Les enfants aborigènes participant à cette étude fréquentaient des groupes de jeu 'Families as First Teachers' (FaFT) (Les familles, premiers éducateurs) en contextes scolaires de deux communautés éloignées du Territoire du Nord. Les données de mise en œuvre de deux composantes (lecture conversationnelle et jeux d'apprentissage) de l'intervention Abecedarian Approach Australia (3a) sont présentées, avec l'analyse du niveau d'exposition des enfants au programme durant la période d'étude. Les résultats des enfants ont été évalués au moyen du test de dépistage Brigance Early Childhood Screen II chez 149 enfants de 24 à 56 mois. Les résultats des enfants en langage et cognition sont associés au niveau d'exposition à l'intervention. Une exposition plus élevée à la lecture conversationnelle et aux jeux d'apprentissage prédit un développement langagier et global plus fort chez les enfants. Cette étude démontre que cette intervention peut être mise en place efficacement auprès de groupes de jeu de zones éloignées. Il s'agit d'une stratégie significative et robuste pour soutenir l'apprentissage en petite enfance, avec le potentiel pour améliorer la réussite éducative des enfants de communautés éloignées.

\section{Resumen}

Nuevos métodos para reforzar el aprendizaje temprano de cultura aborigen en niñas y niños pequeños son vitales para la creación de políticas gubernamentales en toda Australia. El presente estudio explora la posibilidad de que una intervención con el uso del Método Alfabético en Australia (3a), con adaptaciones culturales fuertes, pueda reforzar el lenguaje temprano y las habilidades cognitivas de niños aborígenes, antes del inicio de su educación preescolar. Los participantes en este estudio fueron niños aborígenes que participan en grupos lúdicos, Familias como Primeros Maestros (FaFT, abreviatura en inglés), en ambiente escolar en dos comunidades remotas en el Territorio Norte de Australia. Se reportaron datos de implementación sobre dos componentes (lectura conversacional y juegos de aprendizaje) del Método Alfabético Australiano ( $3 a$ ) y se analizó el nivel de exposición al programa que los niños tuvieron durante el período de investigación. Se evaluaron los resultados de los niños por medio de la Prueba Brigance II de Educación Infantil Temprana en 149 niños entre 24 y 56 meses de edad. El lenguaje y los resultados cognitivos de los niños estuvieron asociados con la dosis de intervención. Una mayor exposición a la lectura conversacional y a los juegos de aprendizaje pronosticó un mayor desarrollo, tanto del lenguaje, como del desarrollo general de niños pequeños. La presente investigación demuestra que este tipo de intervención puede implementarse en forma efectiva en grupos lúdicos en ambientes remotos y constituye una estrategia robusta 
y significativa para reforzar el aprendizaje en la infancia temprana, con la posibilidad de mejorar los resultados educativos de niños en comunidades remotas.

\section{Introduction}

The provision of high-quality early educational experiences for Aboriginal children is an important goal for governments in Australia. In 2011, a report commissioned by the Northern Territory Government, Improving Educational Outcomes in the Northern Territory (Masters 2011) highlighted: '... that low average student performance levels in the Territory, particularly among Indigenous students, have their origins in the years before school. ... The problem is that a large percentage of children begin school significantly behind the rest of Australia and never catch up' (p. 4). This report recommended a search for breakthrough strategies that would support development of English language skills and the early learning skills required by young Indigenous children when they begin school. The Abecedarian Approach consists of a set of language-rich teaching strategies: Language Priority, Enriched Caregiving, Conversational Reading and LearningGames ${ }^{\circledR}$. It provides potential breakthrough strategies that could support early learning prior to school. This research assesses the impact of Abecedarian strategies on young Aboriginal children's language and early learning skills, through participation in child and parent playgroups.

Population measures of child development, such as the Australian Early Development Census (AEDC), confirm that the gap in Aboriginal and non-Aboriginal school achievement throughout Australia is largest in the Northern Territory (Commonwealth of Australia 2018). The 2015 AEDC data, for example, reported that $60 \%$ of Aboriginal children in the Northern Territory are developmentally vulnerable in one or two of the measured domains (physical, social, emotional, language and communication) before they start school compared with $33 \%$ of non-Aboriginal children across Australia. An interrogation of the 2015 AEDC data (Guthridge et al. 2016) confirmed that there was an increased developmental risk across all developmental domains for Aboriginal children compared with non-Aboriginal children, and the greatest areas of inequality are in language and cognition domains. Furthermore, the Grade 3 results in the National Assessment Program Literacy and Numeracy (NAPLAN) in the Northern Territory showed that only $43 \%$ and $50 \%$ of Aboriginal students met or exceeded the national minimum standard for reading and numeracy, respectively, compared with $92 \%$ and $95 \%$ of non-Aboriginal children (Australian Curriculum, Assessment and Reporting Authority 2017). Evidence-based teaching strategies that place priority on language-rich interactions are critical to address the significant gaps in school achievement and the high level of vulnerability of Aboriginal children demonstrated by AEDC data and NAPLAN data.

The potential of Abecedarian strategies to advance Aboriginal children's language development was confirmed in an experimental study in a long day care centre within a community-controlled health service located in Alice Springs, in the Northern Territory (Brookes and Tayler 2016). The study used a single-case experimental research design. Across a period of 16 weeks, 11 Australian Aboriginal children, 
aged between 23 and 36 months, participated in two four-week interventions. Every day in each intervention period, children engaged in a Conversational Reading interaction and a LearningGames interaction with an early childhood educator. The findings indicated that the time children spent interacting in the programme increased by $31 \%$ over the duration of the intervention and that children's use of languages during interactions increased by $18 \%$. A significant improvement in children's Australian English was found following the intervention, '.. with a 7.2 and 6.9 month average increase in age-equivalent scores in Auditory Comprehension and Expressive Communication scores, respectively, over a 4-month period' (Brookes and Tayler 2016, p. 8). While the children's language growth did not maintain the rate of growth following this short intervention, the results highlighted the impact of Abecedarian teaching strategies on young Aboriginal children's learning and development in the short term and the possibility of longer-term improvements with sustained intervention.

\section{Research Context}

In 2009, the Northern Territory Government funded the rollout of Families as First Teachers (FaFT) playgroups, as a voluntary and free programme implemented in school settings, in remote communities across the Northern Territory (Gonski et al. 2018). The aim of FaFT playgroups was to improve the developmental outcomes of young Aboriginal children through high-quality educational programmes and to build mothers' confidence as their children's first teachers. The FaFT playgroups are staffed by a Family Educator, who is an early childhood teacher, and a Family Liaison Officer, who is a local Aboriginal person with early childhood experience. FaFT staff work together in local implementation teams to: (1) ensure cultural competence within the teams, including local language fluency, and (2) deliver an evidence-based early educational programme that builds young children's identity, language, and cultural knowledge. The Abecedarian teaching and learning strategies were adopted as an evidence-based educational programme (AEDC 2014), with Conversational Reading and LearningGames as two main elements of the approach that are implemented and documented in the FaFT early education programmes.

The Abecedarian teaching and learning strategies were selected because of the quality, scale and impact of the empirical research and its well-developed educational focus on children from birth to age 3 years (Campbell et al. 2002). A 'proof of concept' assessment of the strategies for their application in Australian early childhood education and care (ECEC) contexts was undertaken, and they were reviewed and adjusted (The University of Melbourne, n.d.). The aim was to ensure that the core interactional qualities of the strategies were maintained and that these qualities could match with Australian English Language and local cultures (Pilsworth et al. 2017). Such that the Abecedarian Approach Australia ( $3 a$ ) is an adapted version of the original Abecedarian teaching and learning strategies.

There was recognition that in order for the $3 a$ LearningGames to be meaningfully implemented with Aboriginal children and mothers in FaFT playgroups, LearningGames activities needed to be discussed and adapted further in 
consultation with families attending FaFT playgroups with their children. The importance of adapting early childhood educational programme materials to improve cultural responsivity is highlighted by a recent Aboriginal communitydriven project which privileges Aboriginal early childhood knowledge, priorities and practices to develop culturally relevant assessment processes that are appropriate for the contexts (Lowell et al. 2018).

\section{The Current Study}

This research project presented an opportunity to formally assess the impact of Conversational Reading and LearningGames on young Aboriginal children's language and early learning, prior to school, and to explore what level of exposure to these activities is required to have a positive impact. Research in early childhood education is only beginning to examine the ways in which dosage (i.e. levels of exposure to an intervention) is important and to explore what levels of participation are required to make a difference (Wasik et al. 2013).

The aim of this research is to examine the level of dosage for Conversational Reading and LearningGames received in the FaFT playgroups by young Aboriginal children and the impact of that dosage on language and early learning outcomes. We predict that children who receive higher dosage of these early learning activities will show better developmental outcomes.

\section{Methodology}

This study employed a cross-sectional design to track the development of young children and monitor the fidelity of implementation of Conversational Reading and LearningGames within FaFT playgroups across two community sites in the Northern Territory. It measured the dosage children received of $3 a$ activities, across the 3-year period of the project. Child outcomes were measured through a standardised instrument, the Brigance Early Childhood Screen II (Glascoe 2010).

Two remote Aboriginal communities in the Arnhem Land, Northern Territory, were the study sites for this research. These communities had been implementing the $3 a$ educational programme in FaFT playgroups for 3 years and had recorded high levels of child and family attendance. In Community $\mathrm{A}$, there are approximately 2500 people who primarily speak one main language group (Yolyu Matha). In Community B, there are approximately 3000 people who speak over seven language groups (including Burarra, Ndjébbana).

Informed written consent to participate in the study was obtained from a parent or family guardian with the assistance of an Aboriginal staff member at the FaFT programme. Institutional ethics approval was obtained from the relevant committees of two partner organisations (University of Melbourne and Northern Territory Government, Department of Education). 


\section{Sample Characteristics}

The original total cohort comprised 191 children from across two sites (104 in Community A and 87 in Community B). Two cohorts of children were monitored at each community site throughout the 3 -year study. Cohort 1 comprised a group of children born in 2011-2012 $(n=101)$. Cohort 2 included children born in 2014-2015 $(n=90)$. By the time children in Cohort 2 attended FaFT the $3 a$ programme was well embedded; hence the quality, frequency and intensity of the $3 a$ intervention were likely to be higher than for those in Cohort 1. The two cohorts were selected in order to: (1) maximise the number of children who were eligible to participate in the study, and (2) provide a wide range of $3 a$ experience for the cross-sectional analyses.

Of the 191 children who were original participants, there were six withdrawals, over time. Three children were no longer living in the community; two children stopped attending FaFT; and one withdrew for health reasons. Of the remaining 185 children, 149 had received a baseline developmental assessment at 25-58 months and were included in the analyses. There were 87 boys (58\%) in the sample and 62 girls (42\%). There were 71 children (48\%) from Community A and 78 children (52\%) from Community B. This sample included 86 children $(58 \%)$ from Cohort 1 and 63 children (42\%) from Cohort 2 . There were no statistically relevant differences in the distribution of the sample by sex or across communities.

Information on children's first language was recorded for 148 children. There were 13 different languages spoken by the children, and the most common language was Yolnu Matha (Djambarpuyngu) which was spoken by about half of the sample. About a quarter of the sample spoke Burarra as their first language and 11 children spoke Ndjébbana. The remaining languages were spoken by less than six children and mostly by only one or two children in the sample.

\section{Programme Characteristics}

When this project commenced, Conversational Reading and LearningGames had been implemented in two Northern Territory communities for 3 years through daily playgroup sessions, lasting approximately 3 hours. Playgroup sessions were held on five mornings per week in Community A and four mornings per week in Community B, increasing to 5 days a week in the last 12 months of the study. The $3 a$ strategies were also implemented during home visits and in transition-to-preschool programmes in each community. Mothers and family members attended the playgroups with children for the full duration of the sessions.

Conversational Reading involved adult-child interactions that use the Abecedarian 3S strategy (3S-see, show, say), to build children's joint attention, receptive language, comprehension, and expressive language skills. Books used in FaFT programmes are chosen and reviewed by parents in consultation with FaFT staff members. Books written in English have been translated into first language to support Aboriginal mothers' and family members' Conversational Reading practices. 
LearningGames ${ }^{\circledR}$ activities are a set of 200 individualised, educational, gamelike interactions that are shared between an adult and one or two children. Each child experiences one or more LearningGames per playgroup session. The games are simple and embed fundamental learning strategies and the principles of the $3 a$ approach. In 2012, the original 200 LearningGames were adapted to support a sustained approach to implementation in FaFT programmes (The University of Melbourne, n.d.). The process of adaption took place at 15 remote FaFT sites across the Northern Territory. Adaptations included the insertion of culturally relevant pictures of Aboriginal families engaging in the LearningGames and the customisation of LearningGames to ensure integrity and cultural appropriateness (Northern Territory Government 2014). This new suite of LearningGames was reviewed and approved by the Department of Education's Indigenous Early Childhood Parenting Reference Group.

All FaFT staff involved in this project were trained and certified as a $3 a$ Practitioner and $3 a$ Coach to support their knowledge and implementation of the $3 a$ strategies at the FaFT playgroups. In consultation with Professor Joseph Sparling, the original programme developer and a researcher in the Abecedarian studies in the USA, the University of Melbourne developed three training programmes to support a systematic and sustained approach to $3 a$ implementation. Practitioner training takes place over 3 days, and on successful completion of the course, participants are certified as $3 a$ Practitioners. Certification involves the successful completion of a knowledge test following the training, and this was renewed every 12 months to ensure the fidelity of implementation of strategies was maintained over time. Coach training takes place over 1 day, and it has practitioner training as a prerequisite. Participants who become certified $3 a$ Coaches are well equipped to use a range of evidence-based coaching strategies with early childhood professionals, mothers and family members in the implementation of $3 a$ within their organisation.

\section{Observational Measurement of Dosage}

Observational data collected to analyse dosage included children's playgroup attendance and participation in Conversational Reading and LearningGames sessions. Data for Cohort 1 were collected retrospectively (2013-2015), from records kept at FaFT, after which time, data were collected prospectively. All data for Cohort 2 were collected prospectively from 2015 to 2017.

Observation records of child and parent mastery of Conversational Reading and LearningGames were collected throughout the study. These provided a description of adult-child interactions at FaFT. Children and parents were observed participating in the activities together and assessed on indicators such as parent-child engagement, parent-child communication, parent's use of joint attention, and parent's use of concept development. Video recordings of child and parent mastery assessments enabled the research team to check the reliability and consistency of implementation of the activities across sites and over time.

Table 1 provides definitions of the measures of intervention dosage used in these analyses. Dosage was measured in terms of: 
Table 1 Definitions of dosage measures used in the intervention received by children for Conversational Reading and LearningGames

Session

Attendance

Conversational reading $(\mathrm{CR})$ sessions

LearningGames (LG) sessions

Cycle

Conversational reading $(\mathrm{CR})$ cycles

LearningGames (LG) cycles
Total number of days a child and adult attended a FaFT playgroup programme at school, or in the community, or a home visit

Participation by a child and adult in, at least, one conversational reading experience during any attendance day

Dosage classification: low dosage $=0-20$ sessions; medium $=21-80$ sessions; high $=\leq 81$ sessions

Participation by a child and adult in, at least, one LearningGames experience during any attendance day

Dosage classification: low dosage $=0-20$ sessions; medium $=21-80$ sessions; high $=\leq 81$ sessions

Total number of times a child and adult participate in a conversational reading session during any attendance day

Dosage classification: low dosage $=0-40$ cycles; Medium $=41-160$ cycles; high $=\leq 161$ cycles

Total number of times a child and adult participate in LearningGames during any attendance day

Dosage classification: low dosage $=0-80$ cycles; medium $=81-240$ cycles; high $=\leq 241$ cycles

(1) Number of Conversational Reading or LearningGames 'sessions' in which a child participated. A session was a record of whether a child participated in a single Conversational Reading or LearningGames experience on any day;

(2) Number of 'cycles' completed within each Conversational Reading or LearningGames session. A 'cycle' provided information about the number of Conversational Reading experiences on any day (books read or book repetitions) or LearningGames experienced on any day (number of games or game repetitions).

The following definitions were used by staff at the two community sites as the basis to record occurrence of Conversational Reading or LearningGames cycles:

- Conversational Reading cycle Record completion of a Conversational Reading cycle when an adult has read a book with a child (or two children if they are over 36 months of age) using the 'see, show, say' strategy. If the book is read a second time this would be recorded as a second cycle of Conversational Reading. If the book is not completed but the adult has engaged in several (at least four) back and forth exchanges with an adult, record this as a completed cycle of Conversational Reading.

- LearningGames cycle Record a completion of a LearningGames activity when an adult has sat down with a child (or two children if they are over 36 months of age) using several actions described on the LearningGames page and receiving attention, and at least four clear responses from the child. The LearningGames 
pages describe many ways and levels of playing each game, and a particular cycle might include only one or two levels.

\section{Developmental Assessment of Child Outcomes}

The Brigance Early Childhood Screen II was used at various stages in this study to assess child outcomes when children were 2 years, 2.5 years, 3 years, or 4 years of age. The Brigance Screen II was initially chosen because it is a valid and reliable tool, based on over 25 years of research (Glascoe 2002, 2010). The Brigance Screen II includes the following skill areas: language development, early academic skills, and motor skills. This measurement was standardised and validated for children aged from birth to 7 years, across a representative sample in the USA. For use in this study, a number of adaptations were made to the Brigance Screen II in order to improve its cultural appropriateness and the relevance of some items for the children. The majority of children spoke little or no English and usually only the child's first language was spoken at home. The process by which this measure was adapted is described in "Appendix".

Brigance subscale and total scores were transformed into percentile scores according to the age group of the child. These percentile scores (on a 0-100 scale) were then used to compare all children within this study. The Brigance was administered to children at various stages of the study. Cohort 1 were assessed in 2015-2016 when the children were 3-4 years old. Cohort 2 were assessed in 2017 in the final year of the study when children were between 2 and 4 years of age. Only Conversational Reading and Learning Games sessions and cycles that happened before the assessment of child outcomes were considered in the analyses.

\section{Data Analyses}

In this study, dosage is measured as frequencies (e.g. number of sessions and cycles for Conversational Reading and LearningGames). In order to assess the impact of the intervention dosage on child development outcomes, the frequencies of sessions and cycles experienced were categorised into three groups (low, medium, and high dosage; see Table 1 for the cut-off scores). Sessions of Conversational Reading and LearningGames had similar cut-off scores. However, the cut-off scores for Conversational Reading cycles are different from the cut-off scores for LearningGames cycles.

Classifications of low, medium and high dosage groups were determined by inspection of the distributions for each variable and determining clinically meaningful thresholds that could make a difference to children's learning and development. For Conversational Reading and LearningGames, high dosage (more than 80 sessions) represents a child attending FaFT sessions and engaging in Conversational Reading and LearningGames on 2 days a week for a year ( 40 weeks). Low and medium classifications thresholds were then distributed into approximately equal groups. In the categorisation of cycles of Conversational Reading and LearningGames, different cut-offs were applied because of different frequencies in the 
occurrence of these cycles in sessions (e.g. average of 2 Conversational Reading cycles per session; average of 4 LearningGames cycles per session).

\section{Results}

Descriptive statistics are presented in this section. One-way analyses of variance (ANOVA) are then reported to identify differences in child outcomes for playgroup sessions involving Conversational Reading (CR) and LearningGames (LG) sessions, as well as cycles for Conversational Reading (CR) and LearningGames (LG), for low, medium, and high dosage groups.

The average age of the children in the analytic sample at the time of assessment of child outcomes was 37.8 months $(\mathrm{SD}=6.2)$, ranging from 18.6 months to 58.3 months. Children from Community B were slightly older $(M=38.8$ months; $\mathrm{SD}=7.1)$ than children from Community A $(M=36.7$ months; $\mathrm{SD}=4.8)$. Average age at which Brigance outcome assessments were completed, was 39.4 months $(\mathrm{SD}=5.3)$ for Cohort 1 and 35.7 months $(\mathrm{SD}=6.7)$ for Cohort 2 children.

\section{Descriptive Statistics}

Means, standard deviations and range for attendance and other programme participation data for children in the study are presented in Table 2. On average, children attended for 65 days ( $\mathrm{SD}=68.8$ days). Across attendance days, children participated in an average of $42.5 \mathrm{CR}$ sessions and 42.2 LG sessions for LG. There

Table 2 Descriptive statistics for attendance and dosage measures

\begin{tabular}{lrrrll}
\hline Total dosage & $N$ & Mean & \multicolumn{1}{c}{ SD } & Minimum & Maximum \\
\hline Attendance days & 149 & 65.0 & 68.8 & 0 & 490 \\
CR sessions & 149 & 42.5 & 49.2 & 0 & 365 \\
Low dosage & 61 & 8.4 & 6.7 & & \\
Medium dosage & 69 & 44.9 & 16.3 & & \\
High dosage & 19 & 143.4 & 63.9 & & \\
LG sessions & 149 & 42.2 & 47.8 & 0 & 271 \\
Low dosage & 59 & 6.6 & 6.4 & & \\
Medium dosage & 73 & 46.1 & 18.1 & & \\
High dosage & 17 & 149.1 & 51.0 & & \\
CR cycles & 63 & 127.7 & 118.9 & 1 & 509 \\
Low dosage & 15 & 24.6 & 11.9 & & \\
Medium dosage & 31 & 91.9 & 33.0 & & \\
High dosage & 17 & 284.0 & 119.3 & & \\
LG cycles & 63 & 288.1 & 264.8 & 2 & 1144 \\
Low dosage & 11 & 47.8 & 26.4 & & \\
Medium dosage & 23 & 138.7 & 51.4 & & \\
High dosage & 29 & 497.6 & 257.8 & & \\
\hline
\end{tabular}


was an average of $127.7 \mathrm{CR}$ cycles $(\mathrm{SD}=118.9)$ and an average of $288.1 \mathrm{LG}$ cycles $(\mathrm{SD}=264.8)$, on average, for LG cycles. There was no significant difference between the two communities for days of attendance, number of CR and LG sessions, or cycles of CR and LG. Over the study period, in both communities, families became increasingly engaged and an increase in attendance and $3 a$ participation was observed.

\section{Mean Differences in Dosage and Learning Outcomes}

Table 3 provides the results of one-way ANOVAs used to examine if child outcomes on the Brigance assessments for language development, early academic skills, and overall total scores were statistically different across low, medium and high dosage groups for CR and LG sessions and CR and LG cycles. Table 3 presents the F ratios, probability values, and the partial eta values $\left(\eta^{2}\right)$ as indicators of effect size.

There were significant $F$ ratio values for the overall comparison between low, medium, and high dosage groups, across the CR and LG sessions data, indicating an overall difference between groups in each analysis. Post hoc tests conducted then differentiated the differences between groups. High dosage groups had significantly higher mean scores than low dosage groups on language scores and total Brigance scores. Medium dosage groups had higher mean scores than low dosage groups on early academic scores and the total Brigance developmental score.

For the analyses of data for CR and LG cycles, the dosage groups (low, medium, and high) were only able to be constructed for Cohort 2 data. Consequently, there was a smaller sample size in these ANOVA analyses. There were significant F ratio values for the overall comparison between low, medium, and high dosage groups, across CR and LG cycles data, except for the outcome variable of early academic

Table 3 Results of ANOVAs on the four dosage variables categorised as low, medium, high dosage that examined impact on child outcomes measured on the Brigance Early Development Screen II

\begin{tabular}{|c|c|c|c|c|c|}
\hline Independent variable & Brigance outcome & $F$ ratio & $\begin{array}{l}\text { Degrees } \\
\text { of free- } \\
\text { dom }\end{array}$ & Probability & Effect size $\eta^{2}$ \\
\hline \multirow{3}{*}{$\begin{array}{l}\text { CR sessions (low, medium, high } \\
\text { dosage) }\end{array}$} & Language & 3.28 & 2,135 & .04 & .05 \\
\hline & Early academic & 7.36 & 2,138 & $<.001$ & .10 \\
\hline & Total Brigance & 5.57 & 2,133 & $<.01$ & .08 \\
\hline \multirow{3}{*}{$\begin{array}{l}\text { LG sessions (low, medium, high } \\
\text { dosage) }\end{array}$} & Language & 4.45 & 2,135 & .01 & .06 \\
\hline & Early academic & 6.31 & 2,138 & $<.01$ & .08 \\
\hline & Total Brigance & 6.37 & 2,133 & $<.01$ & .09 \\
\hline \multirow{3}{*}{$\begin{array}{l}\text { CR cycles (low, medium, high } \\
\text { dosage) }\end{array}$} & Language & 5.00 & 2,53 & .01 & .16 \\
\hline & Early academic & 3.53 & 2,54 & .04 & .12 \\
\hline & Total Brigance & 5.15 & 2,53 & $<.01$ & .16 \\
\hline \multirow{3}{*}{$\begin{array}{l}\text { LG cycles (low, medium, high } \\
\text { dosage) }\end{array}$} & Language & 3.38 & 2,53 & .04 & .11 \\
\hline & Early academic & 2.02 & 2,54 & .14 & .07 \\
\hline & Total Brigance & 5.43 & 2,53 & $<.01$ & .17 \\
\hline
\end{tabular}


skills for LG cycles. Post hoc tests conducted indicated that high dosage groups had significantly higher mean scores than low dosage groups for language scores and total Brigance development scores. Medium dosage groups had significantly higher mean scores than low dosage groups on the total Brigance development score.

\section{Discussion}

The Abecedarian Approach research undertaken over the past four decades has shown that this evidence-based early childhood intervention can improve children's language and cognitive outcomes. This study adds to this body of evidence, showing that the Abecedarian Approach Australia (3a) implementation in first language with culturally relevant Aboriginal content, can produce positive effects for Aboriginal children's language and academic outcomes. This study highlights the value of two learning strategies, Conversational Reading and LearningGames, for improving children's language and early learning. The implementation of both strategies concurrently with children and parents is important to children's learning outcomes. The observed outcomes are likely due to the effects of the combined strategies, as compared to the result of applying either strategy alone. However, the study design and analyses could not differentiate which of these learning strategies were more important.

The level of $3 a$ dosage required to see an improvement in children's language and early learning skills is an important question for early childhood policy makers and programme managers/educators to consider for future research. While the Brigance language and early learning outcome scores show a stepwise increase from low, medium, to high dosage for Conversational Reading and LearningGames, the absolute ranges of those categories are not definitive. Rather, the categories reflect the distributions in the data and should not be understood as minimum requirements to have programme effects.

\section{Strengths and Limitations of the Research}

The success of the $3 a$ programme can be attributed to the fact that the strategies (Conversational Reading and LearningGames) are relatively simple practices that can be delivered in first language. Parents do not need to be literate in English to share them with their children. Another essential component is that Aboriginal staff were trained in the $3 a$ programme and they provided support for culturally appropriate adaptations, first language interpretations, and the implementation of the programme in first language. Without this ownership by staff and community members, the programme may not have been as successful.

The complex language environments of the Aboriginal families/children are also a consideration. Approximately 120 languages are spoken in Australia (Marmion et al. 2014), with an estimated 80-100 Aboriginal languages and dialects spoken in the Northern Territory, Australia (Butler 2017). Aboriginal children raised in remote communities experience complex language environments and are exposed 
to various language codes, including traditional languages, non-standard varieties of English such as Kriols or Aboriginal English and Standard Australian English (Wigglesworth et al. 2011). In the two remote communities participating in this study, children achieved similar results regardless of the language(s) spoken (one community belonged to one major language group while the other had multiple language groups). This outcome highlights that by implementing the research using a nuanced combination of relevant languages (first language and/or first language with English), the study was able to overcome cultural and language barriers within and between remote communities. Adaptions made to the Brigance screen enabled the research team to use a more culturally and linguistically relevant tool to assess Aboriginal children's outcomes. The series of adaptions overcame many of the cultural, language and logistical issues discussed by D'Aprano et al. (2011).

Programme implementation in a remote Aboriginal community presents a range of challenges. In this study, there were lower levels of attendance, participation in Conversational Reading and LearningGames sessions and home implementation of $3 a$ compared to the levels reported in the original US Abecedarian studies. Despite the lower dosage and limited reports of home implementation, a positive impact on children's language and academic outcomes was evident. The results raise the question of how attendance and dosage can be increased in the future and what strategies and support can be given to raise home implementation in remote Aboriginal communities. This is an important consideration given that a previous study has shown that a home-based Abecedarian early intervention (consisting of biweekly visits during the first 3 years of life) eliminated the developmental gap between children from families with lower versus higher resources (Bann et al. 2016).

Fidelity of implementation and having clear processes to track and monitor the $3 a$ intervention programme as it was intended is an important aspect of the research. The fidelity of coaches, parents and children's interactions was critical for the translation of these results into evidence-based practices. Monitoring of the programme implementation and parent and child mastery of the Conversational Reading and LearningGames is important to assess the quality of coaching and the parent-child interactions. And while not reported in this manuscript, the results provided assurance that the programme was implemented as intended.

A barrier to programme implantation was regular attendance at FaFT. Attendance by a child and caregiver at the FaFT programme was variable within and across the four terms of a year during the research period. In most cases, children were irregular attenders, not attending on a regular (3-5 days/week) basis over the year. Attendance patterns are variable in remote communities due to a range of factors impacting a family's ability to attend (including community, cultural and family commitments, health and socioeconomic factors, seasonal changes in weather, to name a few). When addressing attendance and dosage issues in remote communities, it is important to be conscious of competing priorities for families and communities. We highly recommend home learning support as an additional strategy to overcome some of these barriers to regular attendance at FaFT. A limitation of this study is that children did not attend the playgroups for standard periods of time before being assessed on the Brigance. They were assessed at ages varying from 18.6 to 58.3 months. Because varying ages of assessment and varying lengths of 
treatment are included in the data, the effects of the programme may be underestimated. Given that the days of attendance had a mean of 65 and a standard deviation of 68.8 , this provides some idea of the variability in the opportunities available to make a difference through this intervention.

\section{Conclusions}

The major contribution of this research is that the implementation of $3 a$ teaching and learning strategies through early childhood playgroup programmes is positively associated with Aboriginal children's language and other developmental outcomes. The degree of exposure to Conversational Reading and LearningGames in FaFT playgroups was a predictor of improvements in children's language and overall development. Embedding culture and local language into the $3 a$ programme was an essential component of its success, along with quality of the programme implementation. The outcomes suggest that Abecedarian Approach Australia (3a) delivers a meaningful set of strategies to support early childhood learning (language and overall developmental outcomes) and has the potential to help improve educational outcomes for young Aboriginal children in remote communities.

Acknowledgements This study was supported by the Australian Research Council (ARC) Linkage project 'Building a bridge into preschool in remote Northern Territory communities' and the Department of Education, Northern Territory who were the partners in this grant. We would like to acknowledge the lead work of Emeritus Professor Collette Tayler in the Linkage project. Collette had a keen commitment to improving the educational outcomes of Australian Aboriginal children and was instrumental in setting up this study. Collette passed away in December 2017. We are grateful to the families and community members who participated in the research, and to the FaFT staff who played a critical role in contributing their cultural knowledge and wisdom throughout the implementation of the study. We also thank the Indigenous Early Childhood Parenting Reference Group (IECPRG) for their guidance and contribution.

\section{Compliance with Ethical Standards}

Conflict of interest The authors have no competing financial and/or non-financial interests in relation to the work described. Joseph Sparling is the author of the Abecedarian Approach programme on which the $3 a$ programme used in this study is based. He does not receive royalties or other benefits from the use of the $3 a$ programme.

Open Access This article is distributed under the terms of the Creative Commons Attribution 4.0 International License (http://creativecommons.org/licenses/by/4.0/), which permits unrestricted use, distribution, and reproduction in any medium, provided you give appropriate credit to the original author(s) and the source, provide a link to the Creative Commons license, and indicate if changes were made.

\section{Appendix: Adaptation of the Brigance Early Childhood Screen II}

Many commonly used developmental screening tools are not culturally responsive or appropriate for assessing the skills and behaviours of young Aboriginal children, particularly those living in remote communities (D'Aprano et al. 2011; Lowell et al. 
2018). Because children in this research were very young, decisions were made to administer the developmental screening assessment in children's first language and to use a translator where possible. A number of adaptations were made to the Brigance Early Childhood Screen in order to improve the cultural appropriateness and relevance of some items. Aboriginal staff members were also engaged in the process of adapting and administering the screen. The process of adaptation was iterative and occurred in stages based on feedback from local Aboriginal staff, by mothers and senior community members in both communities.

Prior to the study commencing, the 3-year-old Brigance assessment was trialled with a number of children in each community. Based on feedback from local Aboriginal staff administering the assessment and the responses of children, a number of adaptations were made to improve the cultural relevance of items. For example, on a personal data response, it was noted that Aboriginal children have a range of names, and are often not referred to using a first, middle, and surname. Depending on the community, young Aboriginal children are often called only by their 'mälk' (skin name), or first name. The assessment was adapted accordingly.

After trialling the items with visual prompts (e.g. Picture Vocabulary and Knows Use of Objects) with children, several images were replaced to reflect what the children were more likely to have been exposed to in the community. Based on feedback from Aboriginal staff, a list of suitable answers was developed incorporating sign language, cultural appropriateness and the child's first language. Sign language is a culturally common practice in remote aboriginal communities, and as such sign or gesture is accepted for verbal answers (Page et al. 2017). The majority of children spoke little or no English and usually only first language was spoken at home. Therefore, English language specific items were removed from the analyses if there was no equivalence in first language. All remaining items within the language domain were then evenly weighted so that it was still possible to calculate language domain scores and total scores for the Brigance assessment.

As children entered the study in different age groups, adaptations were also made to items in the 2-year-old screen; 2.5-year-old screen; and 4-year-old screen for the Brigance assessments. These adaptations were made based on changes already made to the 3-year-old assessment and in consultation with Aboriginal research staff at the sites and researchers.

Scoring decisions on the Brigance Screen II for use in these analyses were made based on a review of all responses to each item and consultations within the research team. The research team compared the original items with the adapted items and found higher success rates for almost all of the adapted items, and thus adapted items were used in the analysis. An item with no responses from any child was removed from the assessment as it was deemed inappropriate for the community context.

\section{Examples of Adaptions}




\begin{tabular}{|c|c|c|}
\hline Brigance questions & Original item & Adapted item \\
\hline 1: Identifies body parts & Feet & Hair \\
\hline 3: Picture vocabulary & Key & Spoon \\
\hline 4: Identifies people in pictures & Western family & Aboriginal family \\
\hline 5: Knows use of object & Chair & Chair $^{\mathrm{a}}$ \\
\hline \multicolumn{3}{|l|}{2.5 years old } \\
\hline \multirow[t]{4}{*}{ 2: Identifies body parts } & Fingers & Fingernail \\
\hline & Thumb & Hand \\
\hline & Toes & Feet \\
\hline & Neck & Ear \\
\hline \multirow[t]{2}{*}{ 4: Knows use of objects } & Stove & Campfire \\
\hline & Coat & T-shirt \\
\hline 5: Repeats sentences & English & First language \\
\hline 10.5: Picture vocabulary & Socks & Shoes or thongs \\
\hline 11: Plural s and -ing & $\mathrm{s}$ and -ing & Question removed $^{\mathrm{b}}$ \\
\hline \multicolumn{3}{|l|}{3 years old } \\
\hline \multirow[t]{3}{*}{ 3: Picture vocabulary } & Boat (sailing) & Boat (motor) ${ }^{\mathrm{a}}$ \\
\hline & Kite & Flag \\
\hline & Wool & Fishing line \\
\hline \multirow[t]{2}{*}{ 4: Knows use of objects } & Book & Book $^{\mathrm{a}}$ \\
\hline & Fridge & Fridge $^{a}$ \\
\hline 9: Identifies body parts & Heel & Shoulder \\
\hline 10: Repeats sentences & English & First language \\
\hline 11 Prepositions and irregular plural nouns & Irregular plural & Question removed $^{\mathrm{b}}$ \\
\hline \multicolumn{3}{|l|}{4 years old } \\
\hline \multirow[t]{2}{*}{ 3: Picture vocabulary } & Nail & Fence \\
\hline & Tractor & Bike \\
\hline \multirow[t]{3}{*}{ 8: Identifies body parts } & Heel & Shoulder \\
\hline & Ankles & Elbow \\
\hline & Jaw & Waist \\
\hline
\end{tabular}

${ }^{a}$ Image relevant to community setting

${ }^{\mathrm{b}}$ No equivalence in first language

\section{References}

AEDC (Australian Early Development Census). (2014). Community story: Families as first teachers. Retrieved from https://www.aedc.gov.au/communities/community-stories/story/community-story -families-as-first-teachers.

Australian Curriculum, Assessment and Reporting Authority (ACARA). (2017). NAPLAN achievement in reading, writing, language conventions and numeracy: National report for 2017. Sydney: ACARA. Reprieved from https:/www.nap.edu.au/docs/default-source/default-document-library/ naplan-national-report-2017_final_04dec2017.pdf?sfvrsn=0. 
Bann, C. M., Wallander, J. L., Do, B., Thorsten, V., Pasha, O., Biasini, F. J., et al. (2016). Home-based early intervention and the influence of family resources on cognitive development. Pediatrics, 137(4), e20153766. https://doi.org/10.1542/peds.2015-3766.

Brookes, I., \& Tayler, C. (2016). Effects of an evidence-based intervention on the Australian English language development of a vulnerable group of young Aboriginal children. Australasian Journal of Early Childhood, 41(4), 4-15.

Butler, D. (2017). Vision to reality: Implementing Aboriginal cultural security in the Northern Territory. In: Paper presented at the rural health conference, Cairns.

Campbell, F. A., Ramey, C. T., Pungello, E., Sparling, J., \& Miller- Johnson, S. (2002). Early childhood education: Young adult outcomes from the Abecedarian project. Applied Developmental Science, $6(1), 42-57$.

Commonwealth of Australia, Department of the Prime Minister and Cabinet. (2018). Closing the gapPrime minister's report 2018. Canberra: Author. Retrieved from https://closingthegap.pmc.gov.au/ sites/default/files/ctg-report-2018.pdf?a=1.

D’Aprano, A. L., Carapetis, J. R., \& Andrews, R. (2011). Trial of a developmental screening tool in remote Australian Aboriginal communities: A cautionary tale. Journal of Paediatric Child Health, 47(1-2), 12-17. https://doi.org/10.1111/j.1440-1754.2010.01883.x.

Glascoe, F. P. (2002). The Brigance infant and toddler screen: Standardization and validation. Journal of Developmental Behavioural Pediatrics, 23(3), 145-150.

Glascoe, F. P. (2010). Technical report for the BRIGANCE ${ }^{\circledR}$ Screens. North Billerica, MA: Curriculum Associates Inc.

Gonski, D., Arcus, T., Boston, K., Gould, V., O-Brien, L., Perry, L., et al. (2018). Through growth to achievement: The report of the review to achieve educational excellence in Australian schools. Canberra, ACT: Australian Government.

Guthridge, S., Li, L., Silburn, S., Li, S. Q., McKenzie, J., \& Lynch, J. (2016). Early influences on developmental outcomes among children, at age 5, in Australia's Northern Territory. Early Childhood Research Quarterly, 35, 124-134. https://doi.org/10.1016/j.ecresq.2015.12.008.

Lowell, A., Maypilama, E. L., Fasoli, L., Gundjarranbuy, R., Godwin-Thompson, J., Guyula, A., et al. (2018). Building Yolnu skills, knowledge, and priorities into early childhood assessment and support: Protocol for a qualitative study. JMIR Research Protocols, 7(3), ee50. https://doi.org/10.2196/ resprot.8722.

Marmion, D., Obata, K., \& Troy, J. (2014). Community, identity, wellbeing: The report of the Second National Indigenous Languages Survey. Canberra, ACT: Australian Institute of Aboriginal and Torres Strait Islander Studies. Retrieved from https://aiatsis.gov.au/.

Masters, G. N. (2011). Improving educational outcomes in the Northern Territory: Preliminary advice to the Northern Territory Department of Education and Training, with a particular focus on the ongoing improvement of students' literacy and numeracy achievements. Melbourne, VIC: Australian Council for Educational Research (ACER). Retrieved from https://research.acer.edu.au/.

Northern Territory Government. (2014). NT learninggames ${ }^{\circledR}$. Darwin, NT: Northern Territory Government, Department of Education.

Page, J., Cock, M. L., Thompson, R., Goveas, N., Gapany, D., Chynoweth, L., et al. (2017). The role of gesture and sign language in the early learning of Indigenous children: Implications for the early childhood education pedagogy and practice. In: Paper presented at the little people big dreams conference. Darwin, Northern Territory: Department of Education.

Pilsworth, N., MacBean, C., Tayler, C., Page, J., Eadie, P., \& Niklas, F. (2017). Victorian advancing early learning study. Final report. Melbourne, VIC: Department of Education and Training, Victorian State Government. Retrieved from https://www.education.vic.gov.au/about/research/Pages/publi cations.aspx.

The University of Melbourne, Melbourne Graduate School of Education. (n.d.). The Abecedarian approach Australia. Melbourne, VIC: Author. Retrieved from https://3a.education.unimelb.edu.au.

The University of Melbourne, Melbourne Graduate School of Education and Northern Territory Department of Education. (2014). Position paper: Dual language learning in the 3 a linkage project. Melbourne, VIC: Author.

Wasik, B. A., Mattera, S. K., Lloyd, C. M., \& Boller, K. (2013). Intervention dosage in early childhood care and education: It's complicated. OPRE Research Brief OPRE 2013-15). Washington, DC: Office of Planning, Research and Evaluation, Administration for Children and Families, U.S. Department of Health and Human Services. 
Wigglesworth, G., Simpson, J., \& Loakes, D. (2011). NAPLAN language assessments for indigenous children in remote communities: Issues and problems. Australian Review of Applied Linguistics, 34(3). Retrieved from: http://www.nla.gov.au/ojs/index.php/aral/article/view/2280.

Publisher's Note Springer Nature remains neutral with regard to jurisdictional claims in published maps and institutional affiliations. 